significativa debe darse verdadera e intrinsecamente, sea por atribución, sea sólo por igualdad proporcional..., pues de otro modo sería imposible la predicación por analogía en el discurso metafísico".

$\mathrm{Si}$ "en el principio era la Palabra" quiérese decir con esto que en el fin también, y que en el fondo de todas las cosas está asimismo la palabra: "una estructura inteligible, un logos que la inteligencia -la cual por su parte es también logos- ha de desvelar en la abstracción ideatoria, intuyendo de este modo la verdad y profiriéndola".

La realidad, tanto la humana como la extrahumana, es decantación abisal de la primera Palabra, es toda ella, por lo menos en principio o de derecho, radicalmente inteligible, desvelable, racional, como imagen o vestigio que es de la Razón primera.

Constituye una de las mayores proezas de la inteligencia humana la de haber hecho de éste nuestro pobre lenguaje terreno un instrumento capaz de expresar con sentido las realidades supremas y arcanas.

Con palabras del uso cotidiano, Platón y Aristóteles forjaron el mundo maravilloso de lo intemporal y de lo eternamente válido, o, mejor dicho, nos dieron la llave para franquear el acceso a ese orbe en cuya contemplación radica la felicidad más propia del hombre.

Después de haber ponderado las grandezas de la palabra, reconoce el autor, por otra parte, las miserias del lenguaje filosófico. Las palabras solas no pueden consumar el acto de la posesión espiritual. La filosofía es, como decía Platón, una lucha de gigantes por el ser; es la resolución de conquistar la analogia existencial entre el espíritu y las supremas realidades espirituales, a fin de que la mirada interior pueda abrirse al piélago infinito de la analogia del ser.

La última parte de este estudio se refiere al estilo filosófico. Respecto de este punto proclama "la indiferencia dominadora del espíritu sobre sus medios expresivos. Lo verdaderamente importante y decisivo es fecundar el alma del oyente o del lector a fin de que trascienda... el nombre, la definición y el concepto, y pueda por sí mismo alumbrar y decir su verbo interior..."; para tal fin pueden servir indefinidamente el diálogo, el ensayo o el tratado. Lo importante es que "el estilo filosófico sea siempre directo y dramático, entiéndase bien, de un dramatismo intrínseco, de fondo, es decir, que haya ideas vivas y contrapuestas entre sí, en tensión a la par antagónica y complementaria".

El autor favorece el enriquecimiento progresivo del lenguaje filosófico merced a la introducción de nuevos términos y conceptos, que, en su primer momento, pueden parecer metáforas osadas. Esto debe ser así porque es necesario verter intuiciones inéditas en vocablos dispuestos originariamente para otros usos.

Sin embargo, la metáfora no es el medio exclusivo de expresión filosófica. "El concepto, no obstante todas sus imperfeciones, es, con todo, la vía normal de acceso a la intuición intelectual o del ente verdadero e inteligible."

Este trabajo del doctor Gómez Robledo constituye una valiosa contribución al esclarecimiento de su tema desde el punto de vista profesado por el autor, el de la filosofía escolástica, con algunas nuevas iluminaciones extraídas del pensamiento moderno.

Luis Recaséns Siches

The Impasse in Ethics and a $W$ ay Out, por Brand Blanshard, Howison Lecture. University of California Press, 1955.

Este pequeño folleto, no mayor de veinte páginas, es una de las exposiciones más claras de la situación pre- 
sente de la Ética. Su tesis es que la gran tradición ética parece haber terminado en un callejón sin salida después de dos mil años. La norma de tal ética era "vivir para realizar el mayor bien". Esta norma ha sufrido en nuestros días tres ataques: el primero dirigido contra su fin, el segundo contra su objetividad y el tercero contra su noción del bien. El bien en esta tradición era una simple cualidad no natural que pertenecía evidentemente de suyo a experiencias de varias clases. "No era nada sensible como lo amarillo o lo dulce; no era una cualidad natural si por ella se entiende algo que puede ser observado y medido científicamente. Más aún, era tan simple que caía más allá de todo análisis lógico. Era una de esas nociones fundamentales, como el tiempo y la existencia, acerca de las cuales podemos decir extraordinariamente poco, no obstante que nos son perfectamente familiares... Si hay al. guna teoría ética en que podamos pretender que convergen todas las mentes capaces a partir de Platón y Aristóteles, pienso que es ésta." Blanshard se propone examinar qué es lo que ha quedado de esta teoría después de los ataques que ha sufrido en los años recientes. El primer ataque fue el de los deontólogos, que sostuvieron que la ética comete un error al derivar lo recto del bien; el segundo, el de los positivistas y emotivistas, que afirmaron que el bien no es una cualidad y que, por lo tanto, no es inherente a nada; el tercero fue el de los naturalistas, que insistieron en el hecho de que aunque el bien fuera una cualidad, ésta sería meramente natural, y que, por consiguiente, la ética debe renunciar a sus pretensiones de ser algo más que una ciencia natural.

El ataque "deontológico" se inicia en 1912 con el artículo de H. A. Prichard intitulado "Does Moral Philosophy Rest on a Mistake?" De acuerdo con Prichard, el error surge de conectar el deber con el interés o el provecho. Si yo he hecho una promesa, debo guardarla, no a causa de que sea provechosa, sino simplemente porque debo hacerlo. "Justificar el cumplimiento de las promesas por medio de la búsqueda de provecho es no sólo fútil; es erróneo en principio, pues presupone que el deber se da en función de un posible bien futuro". La idea de Prichard, acerca de que el deber es independiente del bien, fue desarrollada por Sir David Ross en sus dos libros The Right and the Good y Foundations of Ethics. Ross concluye que el deber no tiene nada que ver con la realización del mayor bien; ncasionalmente puede ser deber del hombre escoger una vía que haga peor el mundo. Como se ve, los deontólogos polemizan en contra del bien en un sentido utilitarista. Blanshard no aceptar esta conclusión, puesto que el deber está esencialmente anclado en el arquetipo racional de la vida; entonces, siguiendo el propio deber siempre estaremos de acuerdo con este arquetipo, aunque en ciertos casos particulares pueda parecer que no se está haciendo el bien. En otras palabras, Blanshard sustituye el bien utilitario por una clase diferente de bien racional. Su respuesta a los deontólogos consiste, pues, en que lo recto está basado en el bien y no el bien en lo recto.

De modo similar responde a los positivistas y emotivistas. Los positivistas sostuvieron que no hay algo así como juicios sobre el bien y el mal o sobre lo recto y lo injusto. Hume arguyó que la rectitud de una acción significa solamente que la sociedad, al ver una acción a la luz de sus consecuencias, experimenta una aprobación emotiva en relación a ella. De acuerdo con Westermarck, el juicio acerca de lo recto o lo bueno significa no sólo que la sociedad aprueba algo, sino que uno tiene sentimientos propios de aprobación. La posición subjetivista de Hume y Westermarck, a la que Blanshard denomina subjetivismo histórico o tradicional, ha sido refutada por G. E. Moore en su 
pequeño libro Ethics. Si hay algo claro en nuestras discusiones en torno a problemas morales, dice Moore, es que nuestras creencias chocan a veces. Un subjetivismo que nos dice que tales crencias nunca chocan o pueden chocar, debe desecharse a causa de su abierta discordancia con los hechos. Pero Moore no ha tomado en cuenta el nuevo subjetivismo que surgió subsecuentemente con el emotivismo de Ayer, C. L. Stevenson, Carnap y Reichenbach, que entienden por acuerdo y diferencia no el acuerdo y diferencia en la opinión, sino en la actitud. En este caso, las paradojas contra las cuales luchó Moore nunca surgen porque ". . las sentencias que expresan simplemente juicios morales no dicen nada. Son puras expresiones de sentimientos y como tales no caen bajo las categorías de verdad y falsedad. Son inverificables por la misma razón que lo es un grito de dolor o una voz de mando; porque no ex. presan proposiciones genuinas" (Ayer. Language, Truth and Logic). De este modo, al igual que Prichard, los emotivistas afirman que la filosofía moral se ha basado en un error; pero este error fue el error radical de suponer que nuestros juicios acerca de asuntos morales son realmente juicios.

Blanshard, en su réplica a los emotivistas, acude a su visión racional del valor. La teoría emotivista "puede, de hecho, llegar a desacreditar la noción de justicia interpersonal o internacional". Y justifica su opinión mostrando la inexactitud sistemática del emotivismo en su "descuidado" tratamiento de los juicios de valor. La concepción emotivista debe ceder, pues "nos pide abandonar modos de pensar que están mucho mejor fundados que ella". Es más, el emotivismo es erróneo porque es irreconciliable con nuestro modo de pensar acerca de los valores y porque torna arbitrarias y sin fundamento todas nuestras actitudes. No es de ningún modo plausible interpretar un juicio acerca de los sufrimientos en el campo de concen- tración de Buchenwald como mera expresión de nuestros sentimientos presentes. Las actitudes se dividen, según los emotivistas, en pro y anti actitudes. Pero, ¿por qué deberiamos ver favorablemente, digamos, la felicidad y la educación de nuestros niños y desfavorablemente su ignorancia y miseria? La respuesta natural sería decir que la felicidad y la educación son buenas y la ignorancia y la miseria malas. Pero esta respuesta natural le está impedido darla al emotivista. Para él el hecho no es favorable porque sea bueno; es bueno porque es favorable, y es favorable sin ninguna razón aparente. No hay algo así como el bien objetivo para el emotivista. Esta concepción le parece a Blanshard menos convincente que el antiguo y honorable prejuicio de que hay un bien semejante $y$, en consecuencia, racionalidad y orden en los juicios de valor.

La tercera racha de críticas en contra de la teoría tradicional es la de los intuicionistas, en particualr la de G. E. Moore. Su crítica se dirige contra la distinción entre el "ser" y el "deber" en la teoría tradicional. Cuando los ideales utilitaristas concluyen que el deber consiste en buscar no el mayor placer sino el mayor bien, tienen entre manos la desconcertante cuestión de qué hay que entender por "bien". EI bien es lo que es imputable en común a todas las cosas buenas. Pero ¿qué es? Moore brega con esta cuestión y concluye que lo bueno no es de ningún modo una característica del mundo natural. Nadie ha visto o, más aún, sentido lo bueno. Por poco que pudiera ser sentido podria ser definido. Es tan simple como para ser inanalizable.

Esta reinterpretación de la teoría tradicional fue criticada por los moralistas que no pudieron encontrar tal cualidad en su experiencia propia y que la consideraron como un fuego fauto filosófico que se disuelve cuando se trata de asirlo. Después de un tiempo, el mismo Moore comenzó a dudar de ella. Blans. 
hard está de acuerdo con las críticas de Moore. Le parece difícil comprobar esta cualidad no natural de lo bueno y piensa "que los bienes y los males están más firmemente enraizados en la naturaleza humana de lo que los ideales utilitaristas pueden admitir". Cree que el cumplimiento de los deseos humanos entra en el significado esencial de lo bueno o lo suple en todo o en parte. Comete, pues, lo que Moore denomina la falacia naturalista y perpetra el mismo pecado que reprocha a los emotivistas -ser "descuidado" o muy modesto- en sus análisis. Se conforma con el método socrático de poner distintos ejemplos de valor y sacar a luz lo que tienen en común. "Esto es considerado por algunos analistas actuales como algo muy crudo en cuanto método; pues es posible, dicen, encontrar un grupo de características que esté siempre presente cuando lo bueno lo esté también, y que, con todo, no sea estrictamente lo que lo bueno significa". Blanshard sugiere que "cuando el análisis alcanza esta etapa ha llegado a ser tan refinado como para abolirse a si mismo... Un triunfo de la superficialidad precisa y lúcida". Lo bueno, sostiene, no es una simple cualidad, sino un complejo de caracteristicas de las cuales la palabra es meramente la puerta de entrada. Lo bueno se compone de dos ingredientes: la satisfacción, y la cualidad de la satísfacción, el cum. plimiento. "El gozo no es todo para el bien... Pero es tan esencial para cualquier experiencia que llamemos buena que si desaparece el valor desaparece con él."

Blanshard, por lo tanto, se contenta con una característica psicológica del valor más bien que con analizar el valor mismo. Toma por así decirlo, el rábano por las hojas. Por lo que toca al cumplimiento nos dice: "en la mente de un gran pensador tenemos el más rico cumplimiento de las facultades que nos hacen ser hombres. Tocante a su inteligencia, Sócrates es más hombre que nosotros... el poder, la necesidad, el deseo, de conocer... es un rasgo definitorio de la naturaleza humana". Cuanto mejor cumplimiento damos a esta definición de hombre, tanto más v mejores hombres somos. Una experiencia que es intrínsecamente buena, debe, por ende, primero, satisfacer y en segundo lugar encontrar cumplimiento. El placer sin cumplimiento es difícilmente posible, el cumplimiento sin placer no tiene valor. Blanshard comete claramente la falacia naturalista. "Cumplir y satisfacer aquello a que la naturaleza incita es no sólo bueno; es el sentido de lo bueno." Al definir, pues, lo bueno, Blanshard afirma que ha definido el deber también. El deber es la voz de nuestra naturaleza propia, el imperativo de nuestra propia razón. Nada es bueno si no es consciente, y consciente en la forma articulante de la satisfacción y el cumplimiento del impulso. Lo bueno consiste en la plenitud de la vida, en el cumplimiento de la naturaleza humana. "Ser moral es, en último término, ser natural, razonable y sano."

En tanto que la caracterización de Blanshard del callejón sin salida en que está la Ética es excelente dentro de su concisión, su vía de escape es misma antigua del naturalismo racionalista, que a pesar de los argumentos de Blanshard, Moore ha demostrado como falaz. El naturalismo degrada la Ética al rango de psicología como da a entender el mismo Blanshard. Blanshard tiene razón en fundar la Ética sobre la noción de bien, en lugar de hacerlo sobre lo recto, para mostrar así que los deontólogos están errados. Tiene también razón en mostrar lo absurdo de la teoria emotivista, que es "ingeniosa", pero "ha perdido el rastro en cierto modo". Mas no tiene razón en su crítica de G. E. Moore. La solución del problema de la Ética consiste en la definición del "bien" a la manera iniciada por Moore, la cual no es naturalista ni incomprensible. Tal definición puede aplicarse, generalizan- 
do la solución de Blanshard y hablando no de lo bueno moral, como éste hace -en el sentido de cumplimiento de la naturaleza humana-, sino de lo bueno en general como cumplimiento de la definición de una cosa. A la luz de esta definición del bien, que es más bien lógica que naturalista, la definición de Blanshard se transforma en un caso especial, válido para lo bueno moral.

\section{Robert S. Hartman}

\section{Introdução a Ciencia do Direito, por Paulo Dourado de Gusmão, Edição Revista Forense, Rio de Janeiro, 1956.}

Entre los jóvenes valores del pensamiento jurídico en el Brasil destaca desde hace unos seis años a gran altura Paulo Dourado de Gusmão. Además de un gran número de artículos publicados en varias revistas, se había acreditado ya substancialmente con dos importantes libros: Curso de Filosofia do Direito (1950) y $O$ Pensamento Juridico Contemporaneo (1955). Ahora en esta nueva obra ofrece una excelente introducción a la ciencia del Derecho.

Este libro cubre panorámicamente la introducción a todos los tipos de conocimiento sobre el Derecho. Consta de siete partes: I Teoría Filosófica del Derecho; II. Teoría General del Derecho; III. El Estado; IV. Los Grandes Sistemas Jurídicos (de la ciudad-Estado del Derecho Romano, del Derecho continental, y del Common Law); V. Historia de las Teorías Juridicas; VI. Las Principales Subdivisiones del Derecho Positivo; VII. Las Principales Subdivisiones de la Ciencia del Derecho. El Derecho comparado. La sociología jurídica. La criminología.

Cada uno de los sesenta y cuatro capítulos de este libro va provisto de atinadas indicaciones bibliográficas, y al final de la obra figura un extenso repertorio general.

En una breve reseña no es posible resumir, ni siquiera de modo esquemático, el complejo y rico contenido de este libro. Baste con manifestar que esta obra constituye un óptimo vehículo de introducción a los estudios jurídicos. No sólo al estudiante, sino también al estudioso versado ya en conocimientos jurídicos, este libro le ofrece un bien estructurado panorama y al mismo tiempo un sinnúmero de seductoras incitaciones y de fuertes estímulos para la meditación.

Pero el libro aquí reseñado tiene un notable valor no sólo como instrumento de iniciación. Lo tiene también como un caudal de aportaciones muy estimables al pensamiento jurídico contemporáneo.

Querría destacar algunos de los puntos que me parecen más atractivos en la primera parte de este libro, dedicada a la teoría filosófica del Derecho. El Derecho pertenece al reino construído por el hombre, para el hombre y en función del hombre.

Como conducta humana social, el Derecho tiene un sustrato material (vehículo o soporte, es decir, un comportamiento), además un sentido intencional subjetivo, y también una significación objetiva definida por la norma.

Ninguna captación humana puede agotar los valores jurídicos, pues cabe siempre una nueva comprensión, que puede ser más rica en posibilidades creadoras. Los cambios sociales acarrean la caducidad de algunos valores postulados antes y suscitan nuevos valores. En realidad, Dourado de Gusmão no se refiere tanto a los valores como a las valoraciones humanas históricas sobre la justicia y la seguridad. Ahora bien, estas dos ideas -la de justicia y la de seguridad con sus múltiples y variadas interpretaciones- se combinan con lo que Dourado de Gusmão llama bienes jurídicos, entre los cuales figuran, por ejemplo, el bien- 